\title{
A Theoretical Model for the Relationship between Perceptions, Metaperceptions, and Relational Outcomes
}

\author{
H. Paul LeBlanc III \\ The University of Texas at San Antonio
}

\begin{abstract}
Perception is based on sense experience (Hume, 1748). Whereas, metaperception is perceptions (or ideas) about perception. Relationships are comprised of individuals who develop perceptions of self, perceptions of the relational partner, and perceptions of the relational partners' perception of self and partner (metaperceptions). This article defines perception and metaperception and describes the cognitive components which shape individual's meaning of their experience, and reviews research on perception, metaperception, co-orientation and the impact of these cognitions on relationships and relational quality. This article further reviews more current research on couple construction based upon combinations of perceptions and metaperceptions, then provides a theoretical model for describing relational dynamics as a consequence of communication emanating out of the degree of agreement of perceptions and metaperceptions between relational partners. Finally, this article further provides a direction for future research on improvement of relational outcomes. It is hoped that this theoretical model may prove useful for scholars and practitioners.
\end{abstract}

Keywords: Perceptions. Metaperceptions. Relational outcomes. Cognition. Co-orientation.

\section{INTRODUCTION}

All relationships involve individuals who interact and transact with others based on their knowledge and perceptions of each other, their surroundings, and events. Indeed, all relationships are built on these individual perceptions. Relational outcomes may include degree of trust, level of conflict, and relational satisfaction. With these potential effects, a greater understanding of the influence of relational perceptions and metaperceptions (perceptions about perceptions) is warranted. This paper defines the constructs of perception and metaperception within the context of relationships, and provides a theoretical model explaining the relationship between perceptions, metaperceptions, and the dynamics of relationships.

\section{REVIEW OF LITERATURE}

\section{Foundational Research and Theory on Cognition and Perception}

Perception is a human cognitive process by which sense experience is converted into meaning by individuals. This relationship between sense experience and perception was first formalized by the British philosopher David Hume in his A Treatise of Human Nature (1738) and then expanded upon in his An Enquiry Concerning Human Understanding (1748). Taking Hume's approach, along with the epistemology of Thomas Aquinas, Lonergan (1957) further described the process of human knowledge as comprised of four subprocesses: Perception, thought, question, investigation. Meaning is consequent to these four subprocesses.

Psychologists in the early to mid-twentieth century began looking more closely at the processes of cognition and perception. In the early twentieth century, psychologists conceived of cognitive structures for organizing ideas. Bartlett first labeled these hypothesized cognitive 
structures as schema. According to Bartlett (1932), schemas are not persistent but constantly developing. When new information is received, that information is encoded into the previously existing memory structures. However, advance relevant contextual knowledge is a necessary prerequisite for understanding that new information (Bransford \& Johnson, 1972). The authors demonstrated that when relevant contextual information was provided after new information was provided, comprehension and recall was much lower. More recently, van Kesteren, Ruiter, Fernandez, and Henson (2012) found that information that is congruent with existing knowledge (a schema) is usually better remembered than less congruent information.

Schemas are organized according to expectancies, self-evaluations, rules, and memories (Beck \& Haigh, 2014). Ghosh and Gilboa (2014) posited that cognitive schemas are built upon multiple observations and adaptations to structures of interrelated units, where the detail of the units is less important than the relationships between them. In a recent study, Tse and colleagues (2007) found that memory encoding and consolidation of new information happens very quickly when associative cognitive structures (schema) already exist. Given these findings, a reasonable and justified assumption regarding individuals within interpersonal relationships may be that these individuals develop and adapt perceptions about their relational partners over time.

Communication scholars working within this psychological and epistemological context understand that meaning within individuals is co-constructed through transactional processes with others. The transactional model of "relational" co-constructed meaning was first posited by Barnlund (1970). In Barnlund's transactional model, individuals' perceptions are influenced by messages sent by their relational partners. However, it might be more accurate to describe the co-construction of meaning as a process by which perceptions are modified through transactions with others; that initial perceptions are created through sense experience whether that sense experience occurs through observation or hearing of symbolic exchanges. In other words, perceptions are not created solely through interaction with others but may be subsequently modified through transactions with others.

Indeed, according to McLeod and Chaffee (1973, p. 470):

"a key assumption underlying an interpersonal approach to studying human communication is that a person's behavior is not based simply upon his [sic] private cognitive construction of his world; it is also a function of his perception of the orientation held by others around him and of his orientation to them. A further assumption is that under certain conditions of interaction, the actual cognitions and perceptions of others will also affect his behavior."

\section{Current Research on Perception and Relational Outcomes}

The possibility of modification of perceptions through transactions with others implies that perceptions are malleable. Indeed, LeBlanc argued that "perceptions derive from individual experiences," and that "individuals process information from their experiences to arrive at or construct meaning" (2017, p.1). However, that meaning can be co-constructed through transactional processes suggests that individuals' initial perceptions are not set (see Bartlett, 1932). These perceptions, therefore, are constantly changing. The fact that perceptions change demonstrates that a distinction between what is and what is thought or "known" about what is are distinct.

Effective communication occurs when two-way communication produces high accuracy (Verčič, 2015). In a germinal article, Kenny and Albright (1987) demonstrated that individual accuracy and dyadic accuracy may not match. In describing individual accuracy, the authors 
contend that individuals may behave in reference to their partners based upon their judgements of others. According to Kenny and Acitelli (2001), close relational partners can be both accurate and biased in their perceptions of each other, such as the bias of assumed similarity. The authors found that bias effects were strong when the object of the partner perceptions were related to the relationship itself.

Lack of individual accuracy thus may have relational consequences. In describing dyadic accuracy, the authors contend that individuals may more accurately judge how their partners may interact following co-construction. Increased accuracy in perceptions thus relies upon transaction. These findings support the conclusions of Dornsuch and colleagues (1965) who found that understanding increased between common perceivers, compared to understanding derived at independently between known perceivers, or understanding derived through common cultural experiences.

Biesanz (2010) demonstrated that individuals may be differentially accurate in their perceptions of others. Additionally, individuals may be differentially perceived more or less accurately depending on their self-presentations. These perceptions, accurate or not, may be influenced by characteristics that are observed, but not transactionally shared between relational partners. As Trahan (2011) pointed out, individual identities lying at the intersection of "observable" demographic characteristics influence their experiences and therefore perceptions of the world around them. However, Tagiuri, Blake and Bruner (1952) found that individuals have a greater than chance ability to achieve accuracy in determining the perceptions of others about themselves, and a greater than chance ability to achieve congruency between themselves and others.

\section{Metaperception}

Metaperception, in short, is perception about perception. In relational terms, individuals have perceptions about their relational partners' perceptions. These metaperceptions can be either intrinsic or extrinsic to the relationship. For example, a relationally intrinsic metaperception may include what partner one (A) perceives partner two (B) thinks about partner one or his or her relationship with partner one. A relationally extrinsic metaperception may include what partner one perceives partner two thinks about some external event.

According to Carlson (2016), individuals both initiate and maintain social bonds through metaperceptions. In four separate studies involving new acquaintances, peers, friends and romantic partners, Carlson found that individuals preferred accuracy in metaperceptions from their partners regardless of the positivity of the metaperceptions but enjoyed the relationship more when the metaperceptions were positive. In a related study, Cook and Douglas (1998) found that young adults were generally accurate in their metaperceptions of their fathers' assertiveness and in their parents' cooperation.

In intimate relationships, the importance of positive bias towards the relational partner becomes more pronounced. Boyes and Fletcher (2007) found that individuals perceived that their own partners were positively biased towards them. Additionally, the authors found that metaperceptions of positive bias were more pronounced for partner traits most relevant for evaluation of their mates. Boyes and Fletcher posited that positively biased metaperceptions are a normative feature of intimate relationships. This argument relates well to the findings of Carlson (2016) in how individuals' perception of their partners' positive bias towards them was more enjoyable. Indeed, accurate and positive metaperceptions can significantly impact the maintenance of personal relationships. 


\section{Co-orientation}

Metaperceptions, although occurring when an individual is in a relationship with another, are in the mind of the individual. For interpersonal relationships to continue, some degree of agreement between perceptions and metaperceptions between relational partners must occur. Co-orientation involves relational partners' interdependent perceptions about each other (Newcomb, 1953). According to Clarke (1971), co-orientation requires knowledge about how others evaluate an event. Co-orientation is an interdependency struggle.

Co-orientation between two partners in a relationship involves two sets of perceptions: Direct perceptions and metaperceptions of each individual (Laing, Phillipson, \& Lee, 1966). According to the authors, co-orientation involves three dimensions: a) agreement or actual similarity in direct perceptions; b) comparison between one partner's direct perceptions and the other's metaperceptions, yielding understanding; and c) comparison between one partner's direct perceptions and his or her metaperceptions, yielding congruence. These three dimensions may be described as empathic accuracy, actual and assumed similarity.

Given Laing and colleagues (1966) conceptualization of perceptions involved in relational coorientation, agreement of direct perceptions between relational partners (A) and (B) can be formulized as: $A_{p}=B_{p}$. Understanding between one relational partner's direct perception $\left(A_{p}\right)$ and the other partner's metaperception $\left(B_{m p}\right)$ can be formulized as: $A_{p}=B_{m p}$. Congruence between one partner's direct perceptions and his or her metaperceptions can be formulized as: $A_{p}=A_{m p}$.

Stamm and Pearce (1971) argued that when perception of inaccuracy in the co-orientation process occurs, exchange of information is initiated between partners either by a request for more information, or by giving more information. According to Stamm and Pearce (1971, p. 212), accuracy is defined "as the communicator's discrimination between his [sic] expectations and his perception of what the other said." In other words, a perception of disagreement might motivate initiation of communication.

Interestingly, Kenny and Kashy (1994) found that co-orientation effects (consensus, assimilation, self-other agreement, and assumed similarity) are more pronounced in friendship dyads compared to acquaintance dyads. However, as Burgess (1926) implied, the cultural background or type of relationship may have little influence on psychological process of meaning making. For example, coach-athlete relationships may be characterized as involving co-orientation towards relational closeness, commitment and complementarity (Jowett, 2006). Similar relational characteristics may exist in other quasi-professional/personal relationships. Indeed, all interpersonal relationships may be characterized as requiring transactional coconstruction of meaning about the relationship.

\section{Impact on Relationships}

In same-sex platonic friendships, according to Arroyo and Segrin (2011), perceptions of partners' communication competence were related to relationship satisfaction and commitment. Interestingly, the effect of these perceptions was moderated by metaperceptions of the partner's communication competence. On the other end of the spectrum, McLaren and colleagues (2011) found that relationship uncertainty and perceived interference from a relational partner increased reported relational difficulties. It is important to note that perceived interference from the other implies a judgment of motive. Such judgments are necessarily metaperceptions. Indeed, the individual perceives the partners' motive as intentionally hurtful. A motive is in the mind of the partner (a perception), as judged by the 
individual. As discussed above, a perception of the other persons' perception is a metaperception.

Such judgments about what is in the mind of the other impact all manner of relational characteristics. For example, in a study by Rempel, Holmes and Zanna (1985), interpersonal trust was broken down into three distinct components based upon the individual's judgments about their partner's motives: predictability, dependability and faith. According to the authors, results indicated that all three forms of trust were strongly associated with metaperceptions of the partner's motives. Similarly, Sciangula and Morry (2009) found that self-esteem (a perception about self) influenced individual's perception of their partner's regard (a metaperception). In this sense, perception and metaperception serve as feedback loops for relational maintenance.

Relatedly, Francis, Self and Noble (1982) demonstrated that contextual factors influence communication development between mothers and infants. In particular, the authors note that mutual gaze and visual co-orientation play a significant role in language acquisition. In adult relationships, Rosembaum and Rosenbaum (1975) found that prior perceived similarity of values between a communicator and listeners more strongly influenced attitude change in listeners, when the congruence of values was particularly salient.

These relational effects of perception and metaperception are not limited to healthy individuals. Rather, perception and metaperception influence all relationships. In one study, Sleep, Lavner and Miller (2017) found that individuals with maladaptive personality traits tend to be attracted to potential romantic partners with similar traits. One such trait could be perceived trustworthiness. In a similar study, Miano and colleagues (2017) investigated perceptions of trustworthiness in romantic relationships involving a partner diagnosed with borderline personality disorder (BPD). In a controlled experiment, comparisons between healthy couples and couples with one partner with BPD showed no significant difference in metaperceptions about neutral conversational topics between couple types. However, significant differences between couple types were found in the metaperceptions of trustworthiness of partners when conversations involved threatening situations, such as separation. The researchers concluded that metaperceptions of trustworthiness were more greatly influenced in patients with BPD in threatening situations.

\section{Couple Constructs}

In long-term personal, intimate relationships, couples are typically construed as familial. The essential characteristics of families are the same despite individual differences and differences attributable to various cultural groups (Burgess, 1926). Families grow out of relationships between intimate partners, and between parents and children (Burgess, 1926). These relationships can be unitized as a dyad. Communication creates relationships within these family-based dyads.

From a communication perspective, relationships are initiated and maintained through the feedback loop created between individuals during symbolic transaction. Put another way, couples are constructed through communication. Communication about perceptions helps individuals construct more accurate metaperceptions about their relational partners' internal motivations toward them and the relationship. This transactional process helps build trust. Lack of transaction tends to have the opposite effect. Indeed, coupleness is created through transaction about perceptions and metaperceptions. 
Recent attempts to investigate couple construction have been gaining ground among scholars in social scientific fields outside of communication. For example, medical scholars Martinez and colleagues (2015) argued that increased interest in couple construction demands a precise method for assessing processes of couple construction. The authors offer an assessment tool for measuring perceived similarity, commonality and sociality. In a more recent study, psychologists Freeman, Cassidy and Hay-Smith (2017) conducted a qualitative study utilizing Interpretive Phenomenological Analysis to demonstrate coupleness through communicative activities.

In order to advance the research on relational dynamics as it relates to communicative influences on couple construction which can be utilized by scholars in various fields of social science, a theoretical model for understanding the relationships between perception, metaperception, communication, relational impact, and couple construction must be proposed. Given previous research on co-orientation, the focus on individual perception and metaperception of the relational partner failed to consider the transactional nature of couple construction. In communication research, according to McLeod and Chaffee (1973), the unit of analysis is the dyad. Analysis of any interpersonal relationship must focus on the response of each individual to his or her partner and the perception each individual has of the partner's response (Taguiri, 1952). Indeed, mutual understanding is achieved through effective communication. Therefore, guidance for methodological investigations of relational dynamics will be offered below.

\section{The First Law of Relational Dynamics}

\section{A THEORETICAL MODEL}

All communication ( $\mathrm{T}_{\mathrm{COM}}$ ) entails both effective ( $\mathrm{E}_{\mathrm{COM}}$ ) and ineffective ( $\mathrm{I}_{\mathrm{COM}}$ ) communication.

Effective communication ( $\mathrm{E}_{\mathrm{com}}$ ) occurs when, and only when, both of the following conditions apply: 1$)$ the meta-perception of person $A\left(A_{m p}\right)$ equals the perception of person $B\left(B_{p}\right)$, and 2) the meta-perception of person $B\left(B_{m p}\right)$ equals the perception of person $A\left(A_{p}\right)$.

Ineffective communication ( $\mathrm{I}_{\mathrm{Com}}$ ) occurs when either of the following conditions apply: 1) the meta-perception of person $A\left(A_{m p}\right)$ does not equal the perception of person $B\left(B_{p}\right)$, or 2$)$ the meta-perception of person $B\left(B_{m p}\right)$ does not equal the perception of person $A\left(A_{p}\right)$.

The First Law of Relational Dynamics thus can be formally stated as:

$$
\mathrm{T}_{\mathrm{COM}} \vDash\left\{\left[\mathrm{E}_{\mathrm{com}} \vDash\left(\mathrm{A}_{\mathrm{mp}}=\mathrm{B}_{\mathrm{p}}\right) \&\left(\mathrm{~B}_{\mathrm{mp}}=\mathrm{A}_{\mathrm{p}}\right)\right] \&\left[\mathrm{I}_{\mathrm{com}} \vDash\left(\mathrm{A}_{\mathrm{mp}} \neq \mathrm{B}_{\mathrm{p}}\right) \vee\left(\mathrm{B}_{\mathrm{mp}} \neq \mathrm{A}_{\mathrm{p}}\right)\right]\right\}
$$

\section{The Second Law of Relational Dynamics}

All relationships (R) entail some degree of both effective (Eсом) and ineffective (Iсом) communication.

The Second Law of Relational Dynamics thus can be formally stated as:

$$
\text { All } \mathrm{R} \vDash \mathrm{E}_{\mathrm{COM}^{\circ}}{ }^{\&} \mathrm{I}_{\mathrm{COM}^{\circ}}
$$

\section{The Third Law of Relational Dynamics}

Positive relational change $(+\mathrm{R} \Delta)$ occurs when the degree of effective communication $\left(\mathrm{E}_{\mathrm{COM}}{ }^{\circ}\right)$ is greater than the degree of ineffective communication $\left(\mathrm{I}_{\mathrm{com}}{ }^{\circ}\right)$ and is not the case when the degree of ineffective communication $\left(\mathrm{I}_{\mathrm{Com}}{ }^{\circ}\right)$ is greater than or equal to the degree of effective communication $\left(\mathrm{E}_{\mathrm{COM}^{\circ}}{ }^{\circ}\right.$. 
The Third Law of Relational Dynamics thus can be formally stated as:

$$
+\mathrm{R} \Delta \vDash\left\{\mathrm{E}_{\mathrm{COM}^{\circ}}>\mathrm{I}_{\mathrm{COM}^{\circ}} \& \sim \mathrm{I}_{\mathrm{COM}^{\circ}} \geq \mathrm{E}_{\mathrm{COM}^{\circ}}\right\}
$$

\section{PROPOSED HYPOTHESES}

Given these three laws of relational dynamics, several hypotheses can be proposed to test the relational outcomes based on degree of agreement between perceptions and metaperceptions in relational couples.

$\mathbf{H}_{\mathbf{1}}$ : Interpersonal relationships entail varying degrees of both effective and ineffective communication as assessed by both partners.

$\mathbf{H}_{2}$ : A global assessment of communication within an interpersonal relationship can be assigned along a continuous scale from effective to ineffective by both partners.

$\mathbf{H}_{3}$ : Individuals within an interpersonal relationship may differ in their global assessment of communication along a continuous scale of effective to ineffective.

$\mathbf{H}_{4}$ : Individuals within an interpersonal relationship who have assessed the communication as mostly effective will report higher levels of relational satisfaction.

H5: Individuals within an interpersonal relationship who have assessed the degree of ineffective communication to be equal to or greater than the degree of effective communication will report lower levels of relational satisfaction.

$\mathbf{H}_{6}$ :Positive relational change directly influences relational satisfaction.

These hypotheses are not exhaustive.

\section{METHODOLOGIES FOR INVESTIGATION OF RELATIONAL DYNAMICS}

Communication is the means by which relationships are built and maintained (Knapp, 1978). The symbolic-transactional process of communication is rich with data. According to Smith (1988), human interaction is "marvelously complex." This complexity requires investigation from multiple modes of inquiry (Bochner, Cisna, \& Garko, 1991). For example, any study into the complexities of relationships should begin inductively by observing the behaviors and reactions between individuals engaged in communication.

However, simply observing behavior tells researchers nothing about the internal processes of meaning making for communication participants. In this realm of data collection, interview techniques and methods of textual data analysis must be employed. Scholars, minimally, should conduct interviews with individuals separately and couples together. Through these types of inductive methods, researchers can build categories of potential variables and factors that can be gathered and tested utilizing quantitative approaches. It is not necessary in all cases that data gathering follow the order of observation, interview and survey.

\section{DISCUSSION}

A deeper understanding of the mechanisms of couple construction is required for any study of relationships. As Ruesch and Bateson (1987) argued, the individual is comprised of multiple levels of connection (intrapersonal-psyche, interpersonal-communicative, social-contextual, and anthropological-human). The purpose of this essay is to demonstrate the necessity of a theoretically-grounded, multi-methodological approach for studying relational dynamics.

The fundamental basis for studying relational dynamics, which would include those aspects of relationships which contribute to or detract from positive relational outcomes, is the distinction between effective and ineffective communication. Effective communication occurs when there is agreement among the perceptions and metaperceptions of relational partners, resulting in understanding. Ineffective communication occurs when the degree of 
disagreement among the perceptions and metaperceptions of relational partners is greater than the degree of agreement. If the relational partners share the goal of relational maintenance, then positive relational change should be the desired outcome. Positive relational change could be conceptualized as increases in trust, intimacy, and inclusiveness.

Future research on improvement of relational outcomes should focus on the communicative mechanisms which bring about those outcomes. Previous and current research in the field of communication focuses on these communicative mechanisms. However, research in allied scholarly fields within the social sciences have not yet caught up to the theoretical foundations in the field of communication. As previously stated, relationships are built and maintained through communication which is transactional in nature. Although early communication models described communication as a linear, then interactional process of sending and receiving symbolic messages, as early as 1970 , communication scholars began to understand communication as transactional: that communication is mutually and simultaneously influential. Scholars and practitioners in other social science fields will be well-served to utilize this insight.

\section{References}

Arroyo, A., \& Segrin, C. (2011). The relationship between self- and other-perceptions of communication competence and friendship quality. Communication Studies, 62(5), 547-562. doi:10.1080/10510974.2011.580037

Barnlund, D. C. (1970). A transactional model of communication. In K. K. Sereno \& C. D. Mortensen (eds.), Foundations of Communication Theory, (pp. 83-102). New York: Harper \& Row.

Bartlett, F. C. (1932). Remembering: A Study in Experimental and Social Psychology. Cambridge: Cambridge University.

Beck, A. T., \& Haigh, E. A. P. (2014). Advances in cognitive theory and therapy: The Generic Cognitive Model. In T. D. Cannon \& T. Widiger (Eds.), Annual Review of Clinical Psychology (Vol. 10, pp. 1-24). Palo Alto, CA: Annual Reviews.

Biesanz, J. C. (2010). The social accuracy model of interpersonal perception: Assessing individual differences in perceptive and expressive accuracy. Multivariate Behavioral Research, 45(5), 853-885.

doi:10.1080/00273171.2010.519262

Bochner, A. P., Cissna, K. N., \& Garko, M. G. (1991). Optional metaphors for studying interaction. In B. M. Motgomery \& S. Duck (Eds.), Studying interpersonal interaction (pp. 16-34). New York: Guilford.

Boyes, A. D., \& Fletcher, G. J. O. (2007). Metaperceptions of bias in intimate relationships. Journal of Personality and Social Psychology, 92(2), 286-306. doi:10.1037/0022-3514.92.2.286

Bransford, J. D., \& Johnson, M. K. (1972). Contextual prerequisites for understanding: Some investigation of comprehension and recall. Journal of Verbal Learning and Verbal Behavior, 11, 717-726.

Burgess, E. W. (1926). The family as a unit of interacting personalities. Family, 7, 3-9.

Carlson, E. N. (2016). Meta-accuracy and relationship quality: Weighing the costs and benefits of knowing what people really think about you. Journal of Personality and Social Psychology, 111(2), 250-264. doi:10.1037/pspp0000107

Clarke, P. (1971). Children's response to entertainment: Effects of co-orientation on information-seeking. American Behavioral Scientist, 14(3), 353-\&. doi:10.1177/000276427101400308

Cook, W. L., \& Douglas, E. M. (1998). The looking-glass self in family context: A social relations analysis. Journal of Family Psychology, 12(3), 299-309. doi:10.1037/0893-3200.12.3.299

Dornbusch, S. M., Hastorf, A. H., Richardson, S. A., Muzzy, R. E., \& Vreeland, R. S. (1965). The perceiver and the perceived: Their relative influence on the categories of interpersonal cognition. Journal of Personality and Social Psychology, 1(5). doi:10.1037/h0021864

Francis, P. L., Self, P. A., \& Noble, C. A. (1982). Maternal verbal control techniques with young infants during mutual gaze and visual co-orientation episodes. International Journal of Behavioral Development, 5(3), 317-327. doi: $10.1177 / 016502548200500303$ 
Freeman, C., Cassidy, B., \& Hay-Smith, E. J. C. (2017). Couple's experiences of relationship maintenance and intimacy in acute spinal cord injury rehabilitation: An interpretative phenomenological analysis. Sexuality and Disability, 35(4), 433-444. doi:10.1007/s11195-017-9496-6

Ghosh, V. E., \& Gilboa, A. (2014). What is memory schema? A historical perspective on current neuroscience literature. Neuropsychologia, 53, 104-114. doi:10.1016/j.neuropsychologia. 2013.11.010

Jowett, S. (2006). Interpersonal and structural features of Greek coach-athlete dyads performing in individual sports. Journal of Applied Sport Psychology, 18(1), 69-81. doi:10.1080/10413200500471335

Kenny, D. A., \& Acitelli, L. K. (2001). Accuracy and bias in the perception of the partner in a close relationship. Journal of Personality and Social Psychology, 80(3), 439-448. doi:10.1177/000276427301600402

Kenny, D. A., \& Albright, L. (1987). Accuracy in interpersonal perception: A social relations analysis. Psychological Bulletin, 102(3), 390-402. doi:10.1037/0033-2909.102.3.390

Kenny, D. A., \& Kashy, D. A. (1994). Enhanced co-orientation in the perception of friends: A social-relations analysis. Journal of Personality and Social Psychology, 67(6), 1024-1033. doi:10.1037/0022-3514.67.6.1024

Knapp, M. L. (1978). Social Intercourse: From Greeting to Goodbye. Boston: Allyn \& Bacon.

Laing, R. D., Phillipson, H., \& Lee, A. R. (1966). Interpersonal Perception: A Theory and a Method of Research. New York: Springer.

Lonergan, B. J. F. (1997). Insight: A Study of Human Understanding. Volume 3 of the Collected Works of Bernard Lonergan. Toronto: University of Toronto. Originally published 1957.

Martinez, M. S., Feixas, G., Ballen, C., Munoz, D., \& Compan, V. (2015). The Couple's Grid: A tool for assessing interpersonal construction in couples. Journal of Constructivist Psychology, 28(1), 53-66.

doi:10.1080/10720537.2013.859110

McLaren, R. M., Haunani Solomon, D., \& Priem, J. S. (2011). Explaining variation in contemporaneous responses to hurt in premarital romantic relationships: A Relational Turbulence Model perspective. Communication Research, 38(4), 543-564. doi:10.1177/0093650210377896

McLeod, J. M., \& Chaffee, S. H. (1973). Interpersonal approaches to communication research. American Behavioral Scientist, 16(4), 469-499. doi:10.1177/000276427301600402

Miano, A., Fertuck, E. A., Roepke, S., \& Dziobek, I. (2017). Romantic relationship dysfunction in Borderline Personality Disorder-A naturalistic approach to trustworthiness perception. Personality Disorders-Theory Research and Treatment, 8(3), 281-286. doi:10.1037/per0000196

Newcomb, T. M. (1953). An approach to the study of communicative acts. Psychological Review, 60(6), 393-404. doi:10.1037/h0063098

Rempel, J. K., Holmes, J. G., \& Zanna, M. P. (1985). Trust in close relationships. Journal of Personality and Social Psychology, 49(1), 95-112. doi:10.1037/0022-3514.49.1.95

Rosenbaum, L. L., \& Rosenbaum, W. B. (1975). Persuasive impact of a communicator where groups differ in apparent co-orientation. Journal of Psychology, 89(MAR), 189-194. doi:10.1080/00223980.1975.9915751

Ruesch, J., \& Bateson, G. (1987). Communication: The Social Matrix of Psychiatry. New York: Norton.

Sciangula, A., \& Morry, M. M. (2009). Self-esteem and perceived regard: How I see myself affects my relationship satisfaction. Journal of Social Psychology, 149(2), 143-158.

Sleep, C. E., Lavner, J. A., \& Miller, J. D. (2017). Do individuals with maladaptive personality traits find these same traits desirable in potential romantic partners? Personality and Individual Differences, 119, 317-322.

doi:10.1016/j.paid.2017.08.010

Smith, M. J. (1988). Contemporary communication research methods. Belmont, CA: Wadsworth.

Stamm, K. R., \& Pearce, W. B. (1971). Communication behavior and coorientational relations. Journal of Communication, 21(3), 208-220. doi:10.1111/j.1460-2466.1971.tb00919.x

Tagiuri, R. (1952). Relational Analysis: An extension of sociometric method with emphasis upon social perception. Sociometry, 15(1-2), 91-104. doi:10.2307/2785448

Tagiuri, R., Blake, R. R., \& Bruner, J. S. (1952). Some determinants of the perception of positive and negative feelings in others. Journal of Abnormal and Social Psychology, 48(4), 585-592. doi:10.1037/h0056157 
Trahan, A. (2011). Qualitative research and intersectionality. Critical Criminology, 19(1), 1-14. doi:10.1007/s10612-010-9101-0

Tse, D., Langston, R. F., Kakeyama, M., Bethus, I., Spooner, P. A., Wood, E. R., . . Morris, R. G. M. (2007). Schemas and memory consolidation. Science, 316(5821), 76-82. doi:10.1126/science.1135935

van Kesteren, M. T. R., Ruiter, D. J., Fernandez, G., \& Henson, R. N. (2012). How schema and novelty augment memory formation. Trends in Neurosciences, 35(4), 211-219. doi:10.1016/j.tins.2012.02.001

Verčič, D. (2015). Co-orientation model of public relations. In W. Donsbach (Ed.), The International Encyclopedia of Communication, [Online]. London: John Wiley. Doi:10.1002/9781405186407.wbiecc140.pub2

Logic symbols:

₹ entails (subsumes within)

\& conjunctive (and)

$\checkmark \quad$ disjunctive (or)

$=\quad$ is equivalent to (equals)

$\neq \quad$ is not equivalent to (does not equal)

$\sim \quad$ negation (is not the case) 